\title{
Solid state microcavity dye lasers fabricated by nanoimprint lithography
}

\author{
Nilsson, Daniel; Nielsen, Theodor; Kristensen, Anders
}

Published in:

Review of Scientific Instruments

Link to article, DOI:

$10.1063 / 1.1794411$

Publication date:

2004

Document Version

Publisher's PDF, also known as Version of record

Link back to DTU Orbit

Citation (APA):

Nilsson, D., Nielsen, T., \& Kristensen, A. (2004). Solid state microcavity dye lasers fabricated by nanoimprint lithography. Review of Scientific Instruments, 75(11), 4481-4486. https://doi.org/10.1063/1.1794411

\section{General rights}

Copyright and moral rights for the publications made accessible in the public portal are retained by the authors and/or other copyright owners and it is a condition of accessing publications that users recognise and abide by the legal requirements associated with these rights.

- Users may download and print one copy of any publication from the public portal for the purpose of private study or research.

- You may not further distribute the material or use it for any profit-making activity or commercial gain

- You may freely distribute the URL identifying the publication in the public portal

If you believe that this document breaches copyright please contact us providing details, and we will remove access to the work immediately and investigate your claim. 


\title{
Solid state microcavity dye lasers fabricated by nanoimprint lithography
}

\author{
D. Nilsson, T. Nielsen, and A. Kristensen ${ }^{\text {a) }}$ \\ MIC-Department of Micro and Nanotechnology, Technical University of Denmark (DTU), \\ Building 345 East, Ørsteds Plads, DK-2800 Kongens Lyngby, Denmark
}

(Received 25 February 2004; accepted 25 July 2004; published 29 October 2004)

\begin{abstract}
We present a solid state polymer microcavity dye laser, fabricated by thermal nanoimprint lithography (NIL) in a dye-doped thermoplast. The thermoplast poly-methylmethacrylate (PMMA) is used due to its high transparency in the visible range and its robustness to laser radiation. The laser dye is Rhodamine $6 \mathrm{G} \mathrm{ClO}_{4}$. This dye is shown to withstand temperatures up to $240{ }^{\circ} \mathrm{C}$ without bleaching, which makes it compatible with the thermal nanoimprint lithography process. The $1.55 \mu \mathrm{m}$ thick dye-doped PMMA devices are fabricated on a $\mathrm{SiO}_{2}$ substrate, yielding planar waveguiding in the dye-doped PMMA with two propagating TE-TM modes. The laser cavity has the lateral shape of a trapezoid, supporting lasing modes by reflection on the vertical cavity walls. The solid polymer dye lasers emit laterally through one of the vertical cavity walls, when pumped optically through the top surface by means of a frequency doubled, pulsed Nd:YAG laser. Lasing in the wavelength region from 560 to $570 \mathrm{~nm}$ is observed from a laser with a side-length of $50 \mu \mathrm{m}$. In this proof of concept, the lasers are multimode with a mode wavelength separation of approximately $1.6 \mathrm{~nm}$, as determined by the waveguide propagation constant(s) and cavity dimensions. The stamps used in this work were fabricated by UV-lithography, limiting the lateral dimensional control of the devices. The resolution of NIL is ultimately limited by the quality of the stamps. Using electron beam lithography for stamp fabrication, the NIL process presented here offers the possibility for adding mode-selecting elements, e.g., diffractive- or sub-wavelength optical elements. (C) 2004 American Institute of Physics. [DOI: 10.1063/1.1794411]
\end{abstract}

\section{INTRODUCTION}

Liquid dye lasers ${ }^{1}$ have been a widely used coherent light source with a wide tuning range in the visible part of the spectrum. However, problems associated with handling of the liquid dye solutions, and the size and price of such systems stimulated the research and development of polymer based solid state dye lasers, and other coherent light sources covering the visible range. Solid state dye lasers were realized already in 1967 by Soffer and McFarland ${ }^{2}$ and by Peterson and Snavely, ${ }^{3}$ who demonstrated stimulated emission from a polymer matrix doped with a laser dye. A review on the further development of solid state polymeric dye lasers is given by Singh et ll $^{4}$ Methods for improving the efficiency and lifetime of these devices have attracted much attention. ${ }^{5-7}$

Low cost, maintenance-free polymer based solid state lasers could find applications within communication and sensing systems. In a recent review article, Verpoorte ${ }^{8}$ notes that the integration of optical transducers is a key issue in the further development of "lab-on-a-chip" microsystems. ${ }^{9}$ For such applications polymer based components are an attractive alternative to more commonly used types of solid state lasers. ${ }^{10}$ Most work on solid polymer and other solid state matrices containing laser dyes rely on external and macroscopic laser cavities. Polymer dye lasers with cavities integrated in the polymer structure have been demonstrated by

${ }^{a)}$ Electronic mail: ak@mic.dtu.dk
$\mathrm{Hu}$ and $\mathrm{Kim},{ }^{11}$ and $\mathrm{Li}$ et al.,${ }^{12}$ relying on casting and peeloff. Oki et al. ${ }^{13}$ demonstrated a distributed feed-back laser by holographic UV lithography on a planar, dye-doped waveguide. However, for easy integration, a wafer-scale microfabrication technique is preferable.

Thermal nanoimprint lithography (NIL) ${ }^{14}$ is a hot embossing, parallel lithography technique with nanometer scale resolution, for a review, see Ref. 15. The NIL technique has been used to fabricate polymer based microfluidic devices ${ }^{16}$ and passive optical components. ${ }^{17}$

As a proof of concept we present a polymer microcavity dye laser fabricated by NIL. The laser design is based on guiding of the laser light in a thin film of the thermoplastic polymer poly-methylmethacrylate (PMMA) doped with the laser dye Rhodamine $6 \mathrm{G} \mathrm{ClO}_{4}$, placed on a $\mathrm{SiO}_{2}$ substrate. The lasers have the lateral shape of a trapezoid. They are optically pumped by an external light source, and laterally emitting, as outlined in Fig. 1. The laser resonator relies on total internal reflection at the polymer-air interface at three of the vertical cavity walls, and light is coupled out at the last cavity wall. The cavity design is adopted from Ref. 18, where the microcavities are defined by photolithography in SU-8 photoresist doped with laser dye.

Fabrication by imprint techniques like NIL allows for selecting the polymer and laser dye more freely. The only restrictions to the choice of polymer is that it must be thermoplastic and transparent in the preferred wavelength range. In a previous work, ${ }^{19}$ we have also demonstrated trapezoid and triangular shaped microcavity lasers in dye-doped 


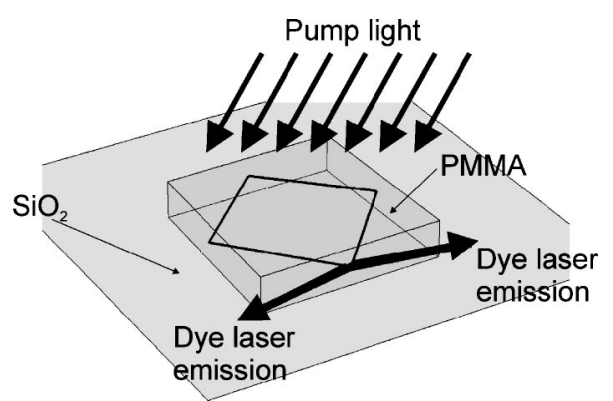

FIG. 1. Outline of the trapezoid shaped PMMA device on a $\mathrm{SiO}_{2}$ substrate. The pump light from an external light source, and the dye laser emission, are indicated.

PMMA, fabricated by reverse imprinting, ${ }^{20}$ where the polymer (dissolved in a suitable solvent) is spin-coated onto the stamp, baked, and subsequently transferred to a substrate.

In NIL, a pattern is transferred from a stamp to a film of thermoplastic polymer on a substrate. The polymer film is heated above its glass transition temperature $\left(T_{g} \simeq 105^{\circ} \mathrm{C}\right.$ for PMMA), typically to a temperature of $70-90{ }^{\circ} \mathrm{C}$ above $T_{g}$, and the stamp is pressed into the polymer. In contrast to conventional hot embossing and injection molding, the NIL technique has limitations when fabricating larger devices (e.g., optical components) with thicknesses of a few microns. The problems are associated with the residual layer thickness under the stamp protrusions and incomplete filling of large cavities in the stamp. ${ }^{21,22}$ A residual layer of the polymer is always remaining on the substrate after imprinting, and the polymer flow decreases rapidly when the residual film thickness decreases.

The Rhodamine-doped PMMA is heated during fabrication, and since most organic dyes are observed to be degraded when heated, ${ }^{4,23,24}$ this has been investigated. Rhodamine $6 \mathrm{G}$ is available in several versions, and the most commonly used is Rhodamine $6 \mathrm{G} \mathrm{Cl}$. This dye is however very sensitive to thermal and optical degradation. We have chosen Rhodamine $6 \mathrm{G} \mathrm{ClO}_{4}$, which is found to be more robust to heating.

In the following sections we present the design considerations for the trapezoid microcavity lasers, the NIL fabrication details, and the optical characterization of the fabricated solid polymer microcavity dye lasers.

\section{THE POLYMER LASER CAVITY}

As illustrated in Fig. 1, the dye-doped PMMA microcavities are placed on a $\mathrm{SiO}_{2}$ substrate. The refractive index of the PMMA increases with the concentration of Rhodamine $6 \mathrm{G} .{ }^{13}$ The value for pure PMMA is $n=1.491$ (at $590 \mathrm{~nm}$ ), and approximately 1.50 for PMMA with a Rhodamine $6 \mathrm{G} \mathrm{ClO}_{4}$ concentration of $25 \mathrm{mM}$. The $\mathrm{SiO}_{2}$ substrate has a smaller refractive index $(n=1.458$ at $590 \mathrm{~nm})$. The structure therefore forms an asymmetric planar waveguide with the dye doped PMMA layer acting as core and the $\mathrm{SiO}_{2}$ substrate as buffer-layer. The Rhodamine 6G laser dye has optical gain at wavelengths between 540 and $610 \mathrm{~nm}$, when it is optically pumped at a wavelength of $532 \mathrm{~nm}$. A polymer height of $1.55 \mu \mathrm{m}$ is chosen to provide sufficient absorption of the pump light. With this polymer height the

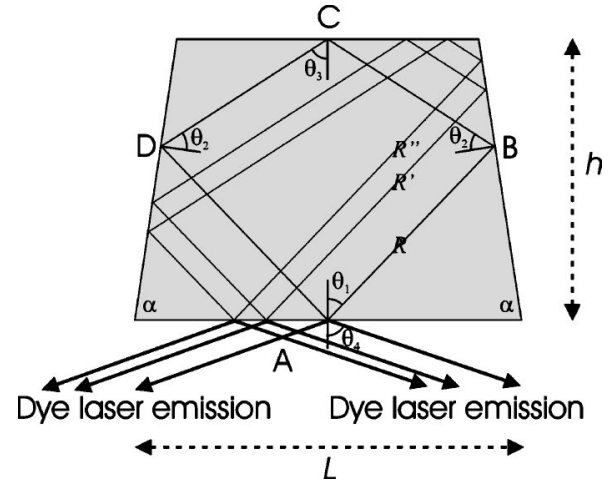

FIG. 2. Design of the trapezoidal microcavity (top view). Light travels in a round trip marked $R$ (or any other parallel round trip, exemplified by $R^{\prime}$ and $\left.R^{\prime \prime}\right)$. The light experiences total internal reflection at $\mathrm{B}, \mathrm{C}$, and $\mathrm{D}$. At $\mathrm{A}$ a fraction of the light is transmitted.

asymmetric waveguide supports two propagating TE-TM modes at wavelengths covered by the dye gain spectrum. ${ }^{25}$

The nanoimprint process leaves a thin residual layer of dye-doped PMMA on the $\mathrm{SiO}_{2}$ substrate surrounding the microcavities. The thickness of this residual layer is determined by the stamp geometry and the initial height of the dyedoped PMMA film. The residual layer thickness is chosen thin enough, 150-200 nm, to avoid guiding of dye laser light outside the imprinted microcavities.

The lasing modes in the trapezoid microcavity are supported by reflection at the vertical polymer walls, as illustrated in Fig. 2. Three closed loop round-trip paths, $R, R^{\prime}$, and $R^{\prime \prime}$, are indicated in the figure. This type of closed loop paths with one reflection at each sidewall all have the same round-trip length, and thereby support the same lasing modes. The entire cavity volume is therefore utilized for amplification of the light. The trapezoid is characterized by the side-length $L$ of the longer base, the trapezoid height $h$, and the angle $\alpha$. These three parameters determine the angles of incidence $\theta_{1}$ and $\theta_{2}$, and the closed loop geometric path-length $l$. The angle of incidence $\theta_{3}$ is given by $\theta_{3}=\pi$ $-2 \theta_{2}-\theta_{1}$.

The devices presented in this atricle are designed with $\theta_{2}=46^{\circ}$ and $\theta_{3}=47^{\circ}$, i.e., the angle of incidence at the three sidewalls, $\mathrm{B}, \mathrm{C}$, and $\mathrm{D}$ is well above the critical angle $\left(\theta_{\text {crit }}\right.$ $=41.81^{\circ}$ ) for the interface between the dye-doped PMMA and air. The angle of incidence at the fourth sidewall A, where the dye laser light is coupled out, is $\theta_{1}=41^{\circ}$, corresponding to a power reflectance of app. 0.2 for horizontally or $p$ polarized (TE) modes, and approximately 0.5 for vertically or $s$ polarized (TM) modes. The dye laser output is emitted laterally, at an angle of refraction $\theta_{4} \simeq 80^{\circ}$, assuming a refractive index around 1.50 for the dye-doped PMMA. Lasing is expected in the TM modes, since these have the highest optical feedback. Likewise, simpler modes, e.g., based on standing waves between the two parallel sides A and $\mathrm{C}$ will have a shorter gain length and lower optical feedback. More complicated modes with more than four reflections per round trip are also expected to have larger cavity losses.

As shown later, the Rhodamine-doped PMMA lasers presented here emit at vacuum wavelengths around $565 \mathrm{~nm}$. 

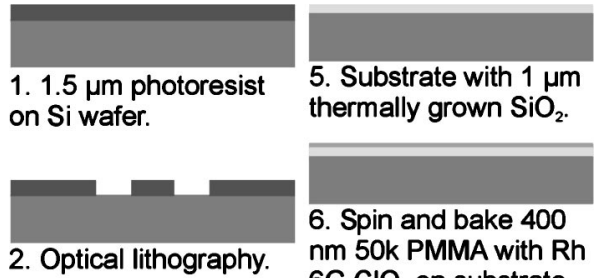

6. Spin and bake 400 $\mathrm{nm}$ 50k PMMA with Rh $6 \mathrm{G} \mathrm{ClO}_{4}$ on substrate.
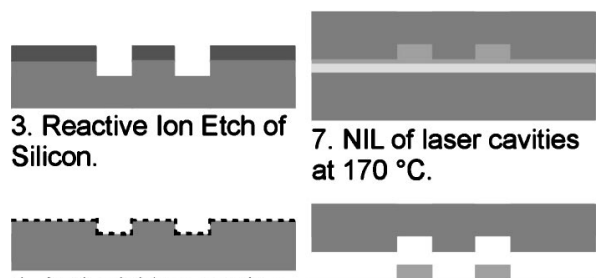

4. Anti-sticking coating in a $\mathrm{C}_{4} \mathrm{~F}_{8}$ atmosphere.

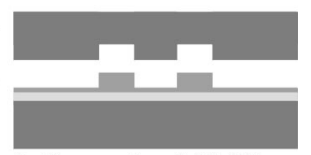

\section{Separate at $90^{\circ} \mathrm{C}$, laser cavities on substrate.}

FIG. 3. Schematic of the process flow for the polymer microcavity dye laser.

With a dye-doped PMMA (refractive index $n=1.50$ ) core layer thickness of $1.55 \mu \mathrm{m}$ and neglecting the finite thickness of the $\mathrm{SiO}_{2}$ buffer layer, we find a propagation constant of $\beta=1.661 \times 10^{7} \mathrm{~m}^{-1}$, corresponding to an effective index of refraction of $n_{\text {eff }}=1.493$ for the lasing $\mathrm{TM}_{0}$ mode. The corresponding values for the $\mathrm{TM}_{1}$ mode are $\beta=1.638$ $\times 10^{7} \mathrm{~m}^{-1}$ and $n_{\text {eff }}=1.473$.

Trapezoid shaped devices scaled to two different sizes are presented here. The first type has $L=10 \mu \mathrm{m}, h$ $=9.82 \mu \mathrm{m}$, and $\alpha=87^{\circ}$. The geometrical path length $l$ is $27.7 \mu \mathrm{m}$, which corresponds to approximately 72 times the dye laser emission wavelength. The mode spacing $\Delta \lambda$ at wavelengths around $565 \mathrm{~nm}$ is $7.7 \mathrm{~nm}$ for $\mathrm{TM}_{0}$ and $7.8 \mathrm{~nm}$ for $\mathrm{TM}_{1}$ modes.

The second type has $L=50 \mu \mathrm{m}, h=49.11 \mu \mathrm{m}$, and $\alpha$ $=87^{\circ}$. In this type of device the path length $l$ is $136.4 \mu \mathrm{m}$, which corresponds to approximately 360 times the dye laser emission wavelength. The mode spacing $\Delta \lambda$ is $1.57 \mathrm{~nm}$ for $\mathrm{TM}_{0}$ and $1.59 \mathrm{~nm}$ for the $\mathrm{TM}_{1}$ modes.

\section{FABRICATION}

The complete process flow for fabrication of the solid polymer microcavity dye lasers includes fabrication of the silicon stamps, preparation of the dye-doped PMMA and the substrate, and finally the imprint process itself.

The silicon stamps used for the NIL process are fabricated by standard microtechnology processes, as outlined in Fig. 3. The microcavities in the stamps are defined by optical lithography and reactive ion etching (RIE). A $1.5 \mu \mathrm{m}$ thick layer of AZ5214E photoresist is used as mask for the RIE process. The RIE process, which is optimized for obtaining vertical and smooth side-walls, is performed in a parallel plate STS Multiplex RIE system with quartz shield. The process pressure is 80 mTorr. $\mathrm{A} \mathrm{SF}_{6}$ flow of $32 \mathrm{sccm}$ is applied together with an $\mathrm{O}_{2}$ flow of $8 \mathrm{sccm}$ and a rf power of $30 \mathrm{~W}$. These parameters give an etch rate of approximately $200 \mathrm{~nm} / \mathrm{min}$. Scanning electron microscope (SEM) images of a silicon stamp after RIE are shown in Fig. 4.

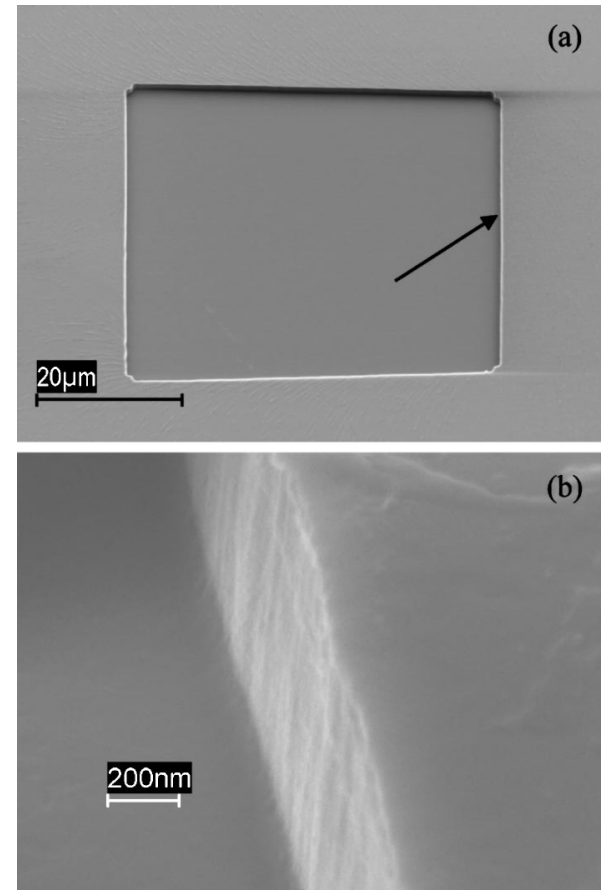

FIG. 4. SEM images of the silicon stamp for a trapezoid shaped solid polymer microcavity dye laser. (a) The length of the output side (to the left) is $L=50 \mu \mathrm{m}$. The arrow indicates the position at which the close-up in (b) is taken.

The stamp is subsequently coated with a teflon like material using a $\mathrm{C}_{4} \mathrm{~F}_{8}$ plasma in a deep reactive ion etcher, as suggested by Ayón et al. ${ }^{26}$ The teflon significantly reduces sticking between the silicon stamp and the polymer during fabrication, allowing easy release of the stamp after imprint.

The silicon substrate wafer, on which the microcavity lasers are fabricated, is prepared with $1 \mu \mathrm{m}$ of thermally grown $\mathrm{SiO}_{2}$. The adhesion between PMMA and $\mathrm{SiO}_{2}$ is generally low, but as stated earlier the $\mathrm{SiO}_{2}$ layer is used to achieve guiding of light inside the cavities.

A thin film, approximately $400 \mathrm{~nm}$ thick, of Rhodaminedoped PMMA is spincoated onto the substrate. The PMMARhodamine solution is prepared by first dissolving Rhodamine in ethanol, and subsequently mixing this with PMMA dissolved in anisole. Rhodamine is poorly dissolved in PMMA, and therefore a polar solvent like ethanol is needed. ${ }^{27} 1 \mathrm{~mL}$ ethanol is used per $20 \mu \mathrm{mol}$ of Rhodamine, and $20 \mu \mathrm{mol}$ Rhodamine is used per gram of PMMA.

The polymer flow, and hence the filling of large stamp cavities during the NIL process, depends strongly on the viscosity of the polymer. The viscosity of PMMA above the glass transition temperature increases strongly with the molecular weight. ${ }^{28}$ Hence a low molecular weight $(50 \mathrm{k})$ PMMA is chosen in combination with a laser dye, that can withstand the elevated temperature necessary to reach the low viscosity regime. Rhodamine $6 \mathrm{G} \mathrm{Cl}$ is one of the most commonly used versions of Rhodamine. PMMA devices doped with this dye, and fabricated by NIL, were observed to show strongly reduced fluorescence.

The thermal bleaching of the dye was investigated. Samples of Rhodamine-doped PMMA were baked at temperatures between 80 and $240{ }^{\circ} \mathrm{C}$ for a time ranging from 


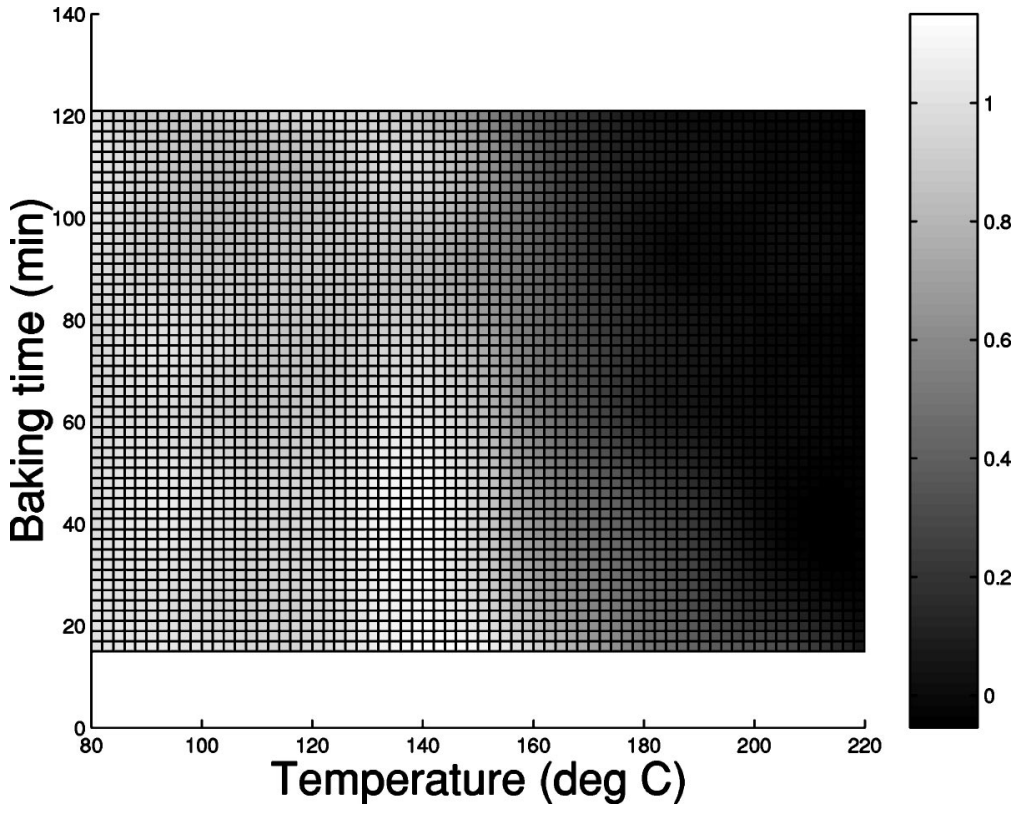

FIG. 5. Fluorescence measurement of Rhodamine $6 \mathrm{G}$ $\mathrm{Cl}$ in PMMA when baked at different times and temperatures. The Rhodamine $6 \mathrm{G} \mathrm{Cl}$ has a strong fluorescence at temperatures up to around $140{ }^{\circ} \mathrm{C}$, but is bleached for higher temperatures. The fluorescence signal is normalized to the signal from a sample baked for $20 \mathrm{~min}$ at $80^{\circ} \mathrm{C}$.
15 to $120 \mathrm{~min}$. The dye was excited at low power (a few $\mathrm{mW} / \mathrm{cm}^{2}$ by a frequency doubled $\mathrm{Nd}$ :YAG laser at wavelength $532 \mathrm{~nm}$ ), and the intensity of the fluorescence from the dye was measured. Figure 5 shows the results for Rhodamine $6 \mathrm{G} \mathrm{Cl}$. It is seen that the fluorescence decreases rapidly from around $140{ }^{\circ} \mathrm{C}$, nearly independent of time at the elevated temperature. Figure 6 shows the results of the fluorescence test on a different type of Rhodamine, Rhodamine $6 \mathrm{G} \mathrm{ClO}_{4}$. Here only small variations in fluorescence can be seen over the whole time-temperature range. Hence the Rhodamine $6 \mathrm{G} \mathrm{ClO}_{4}$ was chosen for the devices presented here.

During the NIL process, the PMMA coated substrate is placed in contact with the stamp inside a homebuilt NIL pressing machine. The chamber of the machine is evacuated down to approximately $0.1 \mathrm{mbar}$, and the stamp and substrate are heated to $170{ }^{\circ} \mathrm{C}$. When this temperature is reached, the stamp and substrate are pressed together under a pressure of approximately $5.5 \mathrm{MPa}$. The pressure and temperature is kept for $10 \mathrm{~min}$, before the stamp and substrate is cooled down. When the temperature reaches $90{ }^{\circ} \mathrm{C}$, the pressure is released and the stamp and substrate are separated. SEM pictures of a $L=50 \mu \mathrm{m}$ side-length trapezoid device are shown in Fig. 7.

\section{CHARACTERIZATION}

For optical characterization the microcavity dye lasers are optically pumped by a pulsed ( $5 \mathrm{~ns}$ pulses at $10 \mathrm{~Hz}$ ) frequency doubled Nd:YAG laser (Continuum Surelite I-10) emitting at $532 \mathrm{~nm}$. Several identical microcavities are pumped simultaneously. The pumping laser beam is coupled into the dye-doped PMMA microcavities through the top surface, and the output from the polymer dye lasers is emitted in the plane parallel to the substrate, as outlined in Fig. 1. The output light is collected by a multimode optical

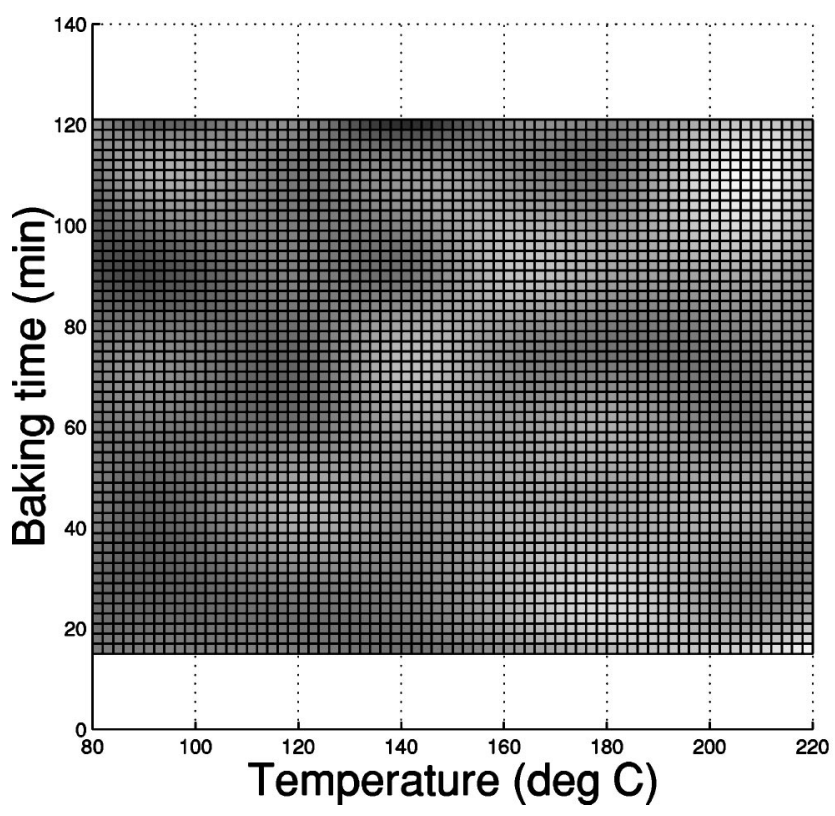

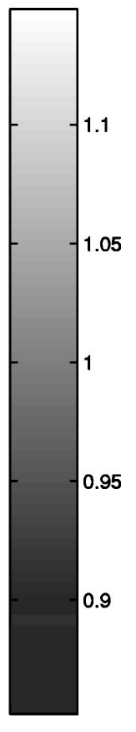

FIG. 6. Fluorescence measurement of Rhodamine 6G $\mathrm{ClO}_{4}$ in PMMA when baked at different times and temperatures. The Rhodamine $6 \mathrm{G} \mathrm{ClO}_{4}$ does not show significant bleaching in contrast to Rhodamine $6 \mathrm{G} \mathrm{Cl}$ (see Fig. 5). The fluorescence signal is normalized to the signal from a sample baked for $20 \mathrm{~min}$ at $80{ }^{\circ} \mathrm{C}$. It should be noted that the fluorescence of an unbleached Rhodamine $6 \mathrm{G} \mathrm{ClO}_{4}$ sample is approximately $50 \%$ larger than the unbleached Rhodamine $6 \mathrm{G} \mathrm{Cl}$ sample. 


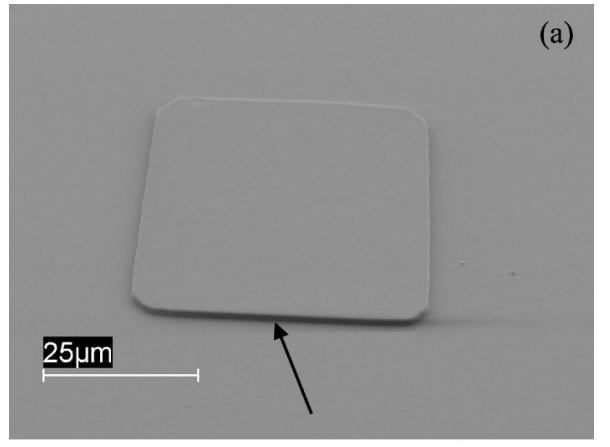

(b)

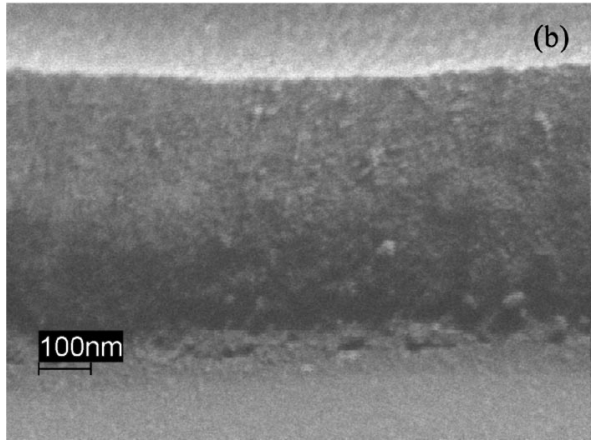

FIG. 7. SEM images of a trapezoid shaped solid polymer microcavity dye laser. (a) The length of the output side (to the left) is $L=50 \mu \mathrm{m}$. The arrow indicates the position at which the closeup in (b) is taken.

fiber (200 $\mu \mathrm{m}$ core diameter), placed within one centimeter from the sample, in the plane of the sample. The light is analyzed by a fixed grating spectrometer (AVS-USB2000 from Avantes).

Figure 8 shows the output from a trapezoid shaped device with a side length of $L=50 \mu \mathrm{m}$ fabricated by NIL. Three spectra, measured at different optical pumping intensities, 35, 184, and $332 \mathrm{~mW} / \mathrm{cm}^{2}$, are shown. The laser exhibits multimode oscillations. A series of double and triple peaks are observed with the predicted period of approximately $1.6 \mathrm{~nm}$. The observed double and triple peak structure can be due to the small difference in propagation constants of the lasing $\mathrm{TM}_{0}$ and $\mathrm{TM}_{1}$ modes. Small variations in size of the lasing devices can also contribute to the complicated details of the observed emission spectra. The inset shows the PMMA microcavity dye laser output intensity ver-

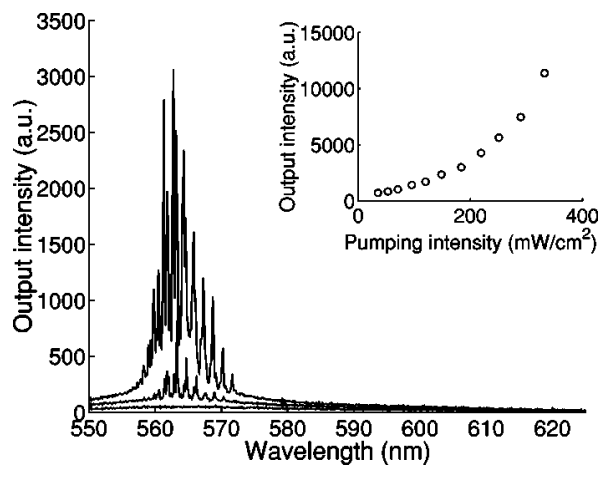

FIG. 8. Output spectra from an array of trapezoid shaped devices with $50 \mu \mathrm{m}$ side length, at different pumping intensities: 35, 184, and $332 \mathrm{~mW} / \mathrm{cm}^{2}$. The laser is multimode. The inset shows the output intensity at different pumping intensities. The change in slope indicates the onset of laser operation.

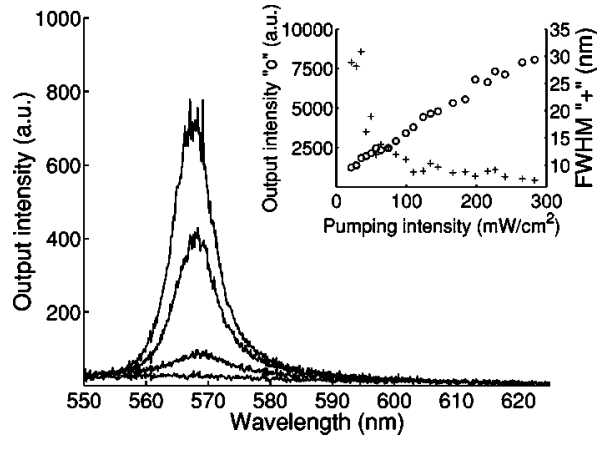

FIG. 9. Output spectra from an array of trapezoid shaped device with $10 \mu \mathrm{m}$ side length, at different pumping intensities: $21,64,166$, and $283 \mathrm{~mW} / \mathrm{cm}^{2}$. The inset shows the output intensity and the FWHM at different pumping intensities. There is no change in slope in the output intensity to indicate the threshold for laser operation, only in the FWHM.

sus pumping intensity. The change in slope indicates the onset of lasing. The efficiency of the lasers is estimated to approximately $0.1 \%$. The dye laser light is emitted laterally at an angle of refraction of $\theta_{4} \simeq 80^{\circ}$, in accordance with our design considerations. The emitted dye laser light is vertically polarized, as expected from the assumption of lasing TM modes. The lifetime of the laser devices was also measured. At a pumping intensity of $195 \mathrm{~mW} / \mathrm{cm}^{2}$, the dye laser output was reduced by $3 \mathrm{~dB}(50 \%)$ after 12000 pulses, or $20 \mathrm{~min}$.

Figure 9 shows the output from a trapezoid shaped device with a side length of $L=10 \mu \mathrm{m}$. The spectra are different from the five times larger devices in Fig. 8. The inset shows that there is no change in slope in the output intensity as function of pumping intensity, but there is a significant drop in the full width half maximum (FWHM). This could be an indication of amplified spontaneous emission ${ }^{29}$ rather than lasing from the smaller devices, where the quality of the fabricated polymer cavities is limited by the resolution of the UV-lithography step used for the stamp fabrication.

D.N. wishes to thank the Center for Microinstruments (CfM) and Sensor Technology Center A/S (STC) for their financial support. The work was supported by the Danish Technical Research Council (STVF, Grant No. 26-02-0064).

${ }^{1}$ F. P. Schäfer, Dye Lasers (Springer-Verlag, Berlin, 1990).

${ }^{2}$ B. H. Soffer and B. B. McFarland, Appl. Phys. Lett. 10, 266 (1967).

${ }^{3}$ O. G. Peterson and B. B. Snavely, Appl. Phys. Lett. 12, 238 (1967).

${ }^{4}$ S. Singh, V. R. Kanetkar, G. Sridhar, V. Muthusawamy, and K. Raja, J. Lumin. 101, 285 (2003).

${ }^{5}$ R. M. O'Connell and T. T. Saito, Opt. Eng. 22, 393 (1983).

${ }^{6}$ S. Popov, Appl. Opt. 37, 6449 (1998).

${ }^{7}$ W. J. Wadsworth, S. M. Giffin, I. T. McKinnie, J. C. Sharpe, A. D. Woolhouse, T. G. Haskell, and G. J. Smith, Appl. Opt. 38, 2504 (1999).

${ }^{8}$ E. Verpoorte, Lab Chip 3, 42N (2003).

${ }^{9}$ A. Manz, N. Graber, and H. M. Widmer, Sens. Actuators B 1, 244 (1990).

${ }^{10}$ L. Lindvold and L. Lading, Proc. SPIE 3276, 220 (1998).

${ }^{11}$ C. Hu and S. Kim, Appl. Phys. Lett. 29, 582 (1976).

${ }^{12}$ Y. Li, M. Sasaki, and K. Hane, J. Micromech. Microeng. 11, 234 (2001).

${ }^{13}$ Y. Oki, T. Yoshiura, Y. Chisaki, and M. Maeda, Appl. Opt. 41, 5030 (2002).

${ }^{14}$ S. Y. Chou, P. R. Krauss, and P. J. Renstrom, Appl. Phys. Lett. 67, 3114 (1995).

${ }^{15}$ H.-C. Scheer, H. Schulz, T. Hoffmann, and C. M. Sotomayor Torres, "Nanoimprint Techniques", in Handbook of Thin Film Materials, edited by H. S. Nalwa, Vol. 5, Nanomaterials and Magnetic Thin Films (Aca- 
demic, New York, 2002).

${ }^{16}$ V. Studer, A. Pepin, and Y. Chen, Appl. Phys. Lett. 80, 3614 (2002).

${ }^{17}$ J. Seekamp, S. Zankovych, A. H. Helfer, P. Maury, C. M. Sotomayor Torres, G. Böttiger, C. Liguda, M. Eich, B. Heidari, L. Montelius, and J. Ahopelto, Nanotechnology 13, 581 (2002).

${ }^{18}$ S. Kragh, S. Balslev, and A. Kristensen, Proceedings of the Seventh International Conference on Miniaturized Chemical and Biochemical Analysis Systems ( $\mu$ TAS 2003), Squaw Valley, California, 5-9 October (The Transducers Research Foundation, 2003), p. 1331.

${ }^{19}$ D. Nilsson, T. Nielsen, and A. Kristensen, Microelectron. Eng. 73-74, 372 (2004).

${ }^{20}$ X. D. Huang, L.-R. Bao, X. Cheng, L. J. Guo, S. W. Pang, and A. F. Yee, J. Vac. Sci. Technol. B 20, 2872 (2002).

${ }^{21}$ H. Schift, L. J. Heyderman, M. Auf der Maur, and J. Gobrecht, Nanotechnology 12, 173 (2001).
${ }^{22}$ L. J. Heyderman, H. Schift, C. David, J. Gobrecht, and T. Schweizer, Microelectron. Eng. 54, 229 (2000).

${ }^{23}$ F. Higuchi and J. Muto, Phys. Lett. 81A, 95 (1981).

${ }^{24}$ K.-C. Yee, T.-Y. Tou, and S.-W. Ng, Appl. Opt. 37, 6381 (1998).

${ }^{25}$ R. G. Hunsperger, Integrated Optics: Theory and Technology, 5th ed. (Springer-Verlag, Berlin, 2002).

${ }^{26}$ A. A. Ayón, D.-Z. Chen, R. Khanna, R. Braff, H. H. Sawin, and M. A. Schmidt, Mater. Res. Soc. Symp. Proc. 605, 141 (2000).

${ }^{27}$ A. Maslyukov, S. Sokolov, M. Kaivola, K. Nyholm, and S. Popov, Appl. Opt. 34, 1516 (1995).

${ }^{28}$ H. Schift and L. J. Heyderman, in Nanorheology, Squeeze Flow in Embossing of Thin Films, Alternative Lithography, volume editor C. Sotomayor Torres, in Nanostructure Science and Technology, edited by D. J. Lockwood (Kluwer Academic/Plenum, 2003).

${ }^{29}$ O. Svelto, Principles of Lasers, 4th ed. (Plenum, New York, 1998). 